\title{
ADAPTING REFLECTANCE TRANSFORMATION IMAGING (RTI) TO SUBOPTIMAL FIELD CONDITIONS PRESENTED BY LARGE-SCALE LANDSCAPE MONUMENTS: THE CASE OF THE YALBURT YAYLASI SACRED POOL COMPLEX
}

\author{
YANSITMA DÖNÜŞÜMLÜ GÖRÜNTÜLEME'NİN (RTI) BÜYÜK ÖLÇEKLİ PEYZAJ \\ ANITLARININ SUNDUĞU ZORLAYICI KOŞULLARA UYARLANMASI: YALBURT YAYLASI \\ KUTSAL HAVUZ ANITI ÖRNEĞI
}

\section{MÜGE DURUSU-TANRIÖVER*}

\begin{abstract}
Reflectance Transformation Imaging (RTI) was used to record an inscription carved on the surfaces of 17 limestone blocks of the Yalburt Yaylası Sacred Pool Complex (Konya), which dates from the XIII ${ }^{\text {th }}$ century B.C. After a brief introduction concerning the site and the RTI technique, and particularly its Highlight-RTI variant, this paper reports on the imaging strategy tailored to the conditions of this specific landscape monument, which contains blocks of various dimensions organized along three axes. While various applications of the RTI technique on open-air examples have been reported in the literature to date ${ }^{1}$, our experience on the Yalburt Yaylası Sacred Pool Complex presents a large-scale application of Highlight-RTI on a complex monument. The paper concludes that RTI is an efficient tool for documenting landscape monuments when the needs of each site are carefully analyzed. In this large-scale capacity, RTI works best as a site-specific technique customized to the particularities of each locale.
\end{abstract}

Keywords: Reflectance Transformation Imaging (RTI) - Highlight-RTI • Yalburt Yaylası Sacred Pool Complex - Landscape monument • Archaeological Imaging
Öz: MÖ XIII. yüzyıla tarihlenen Yalburt Yaylası Kutsal Havuz Kompleksi'nde (Konya) 17 adet kireçtaşı bloğun yüzeylerine kazınmış yazıtın kayıt altına alınması için Yansıtma Dönüşümlü Görüntüleme (Reflectance Transformation Imaging, RTI) kullanılmıştır. Anita ve RTI'ın Highlight-RTI moduna dair kısa bir girişin ardından makale üç farklı yönde ve farklı özelliklerde bloklar içeren Yalburt anıtının sunduğu özel koşullar için tasarlanmış görüntüleme stratejisini anlatmaktadır. Her ne kadar RTI’ın açık havada kullanıldığı başka örneklere daha önce literatürde yer verilmiş olsa da, Yalburt Yaylası Kutsal Havuz Kompleksi'ne dair deneyimimiz Highlight-RTI’n pek çok bileşeni olan bir kaya anıtı özelinde nasıl büyük ölçekli bir uygulama olabileceğini göstermektedir. Makale, yerel gereklilikler detaylı şekilde analiz edildiği takdirde RTI’ın kırsal peyzajda konumlanmış kaya anıtlarının kayıt altına alınması için etkili bir yöntem olabileceğini önermektedir. Sonuç olarak, kaya anıtlarının bu teknikle görüntülenmesinde en iyi sonuçların alınabilmesi için RTI’nn yerel koşullara uyarlanan ve o yere özgü bir biçimde özelleştirilmiş bir teknik olarak ele alınması gerektiği ortaya konulmaktadır.

Anahtar Kelimeler: Yansitma Dönüşümlü Görüntüleme (RTI) • Highlight-RTI • Yalburt Yaylası Kutsal Havuz Anıtı • Kaya Anıtı • Arkeolojik Görüntüleme

* Asst. Prof. Dr., Bilkent University, Faculty of Art, Design and Architecture, Department of Urban Design and Landscape Architecture, Ankara. (0000-0002-0734-7301 | muge.durusu@bilkent.edu.tr

1 E.g. Mudge et al. 2006; Frood - Howley 2014; Akçay 2016. 
Located in the highlands north of the Ilgin Plain (Konya) and on a prolific spring now moved to sustain the neighboring villages, the Yalburt Yaylası Sacred Pool Complex is one of the most impressive landscape monuments of the Hittite Empire (Fig. 1)2. Once lining the pool supplemented by the aforementioned spring, a series of limestone blocks were carved with a long inscription in hieroglyphic Luwian, recording the details of a military campaign undertaken by the Hittite king Tudhaliya IV at the end of the XIII ${ }^{\text {th }}$ century to the southwestern borderlands of his empire ${ }^{3}$. A partially preserved relief depicts Tudhaliya under the embrace of a mountain deity, and emphasized this king's attachment to sacred mountains ${ }^{4}$. The Hittite monument was reincarnated as a smaller Roman pool in the later centuries, before it was gradually buried under a thick deposit ensuring the protection of the limestone blocks until the $20^{\text {th }}$ century ${ }^{5}$.

As infrastructure work to move the spring was being done in the area in 1970, the soundings hit the inscribed blocks and work was immediately suspended ${ }^{6}$. Archaeological excavations began the following year under the supervision of the Ankara Anatolian Civilizations Museum ${ }^{7}$. A total of 22 blocks with inscription were discovered at the site, along with other inscribed pieces. Compared with the 17 blocks currently at the site, the original inscription seems to have been longer. As the blocks were re-exposed to the elements, their protection became an important issue, and the Ankara Museum constructed a canopy over the monument in 1975. When not maintained, the roof fell apart. This meant that the monument was totally exposed to weather, but also that chunks of the roof - metal rods embedded in concrete footings - were leaning on the blocks and caused serious damage?

Since 2010, the Yalburt Yaylası Sacred Pool Complex and its surroundings have been systematically investigated by the Yalburt Yaylası Archaeological Landscape Research Project, directed by Dr. Ömür Harmanşah (UIC), with Dr. Peri Johnson (UIC) as the field director. One of the key issues our project tackles is the site of Yalburt Yaylası itself, including the sacred pool monument, its associated contemporary settlement and its landscape context. Our annual visits to the Yalburt Monu-

2 Fieldwork required for the Reflectance Transformation Imaging on the Yalburt monument was carried out with the permission of the Ministry of Culture and Tourism in the Republic of Turkey, as part of the Yalburt Yaylası Archaeological Landscape Research Project directed by Assoc. Prof. Dr. Ömür Harmanşah of the University of Illinois at Chicago (2014 permit issue date 19.June.2014, number 119360; 2016 permit issue date 30.June.2016, number 124625). Funding for the 2014 season was provided by University of Texas at Austin and Brown University. Funding for the 2016 season was provided by the University of Illinois at Chicago. I am grateful to Dr. Harmanşah and Dr. Peri Johnson for allowing me to carry out and publish the RTI project. I would also like to extend my thanks to Hasan Fidan, Yusuf Varmış and Nar Johnson-Harmanşah, who helped with the physically demanding RTI work. I am also grateful to Kathryn Howley for introducing me to RTI, as well as for her help in answering questions during our fieldwork seasons; and to Linda Gosner, Kathryn McBride, Catherine Steidl and the two anonymous referees for their comments on the present manuscript. Any mistakes and oversights remain my own.

3. Hawkins 1995.

4 Harmanşah et al. 2017,310.

5 Temizer 1984, xvi.

6 Harmanşah et al. 2014, 10.

7 Temizer 1984, xxv-xxvii.

8 Temizer 1984, xvi.

9 Harmanşah-Öz 2018, 11. 


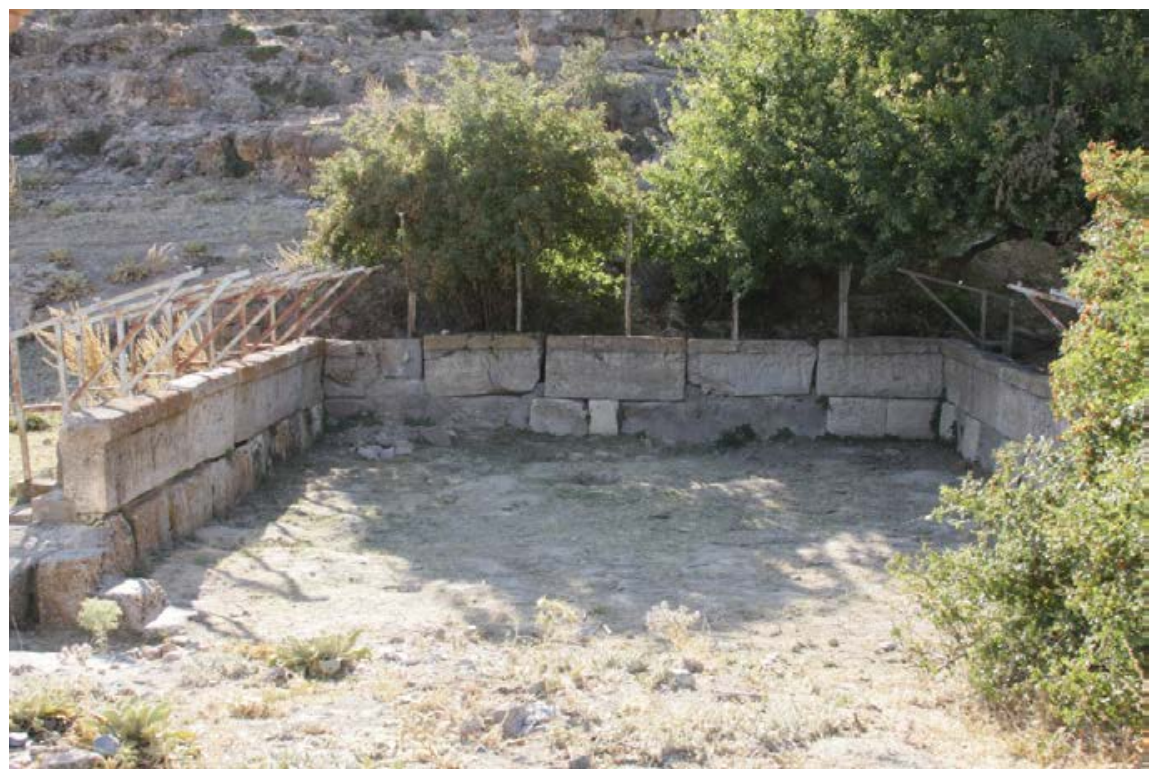

Fig. 1. Yalburt Yaylası Sacred Pool Monument

(photo by Ömür Harmanşah, (C) Yalburt Yaylası Archaeological Landscape Research Project)
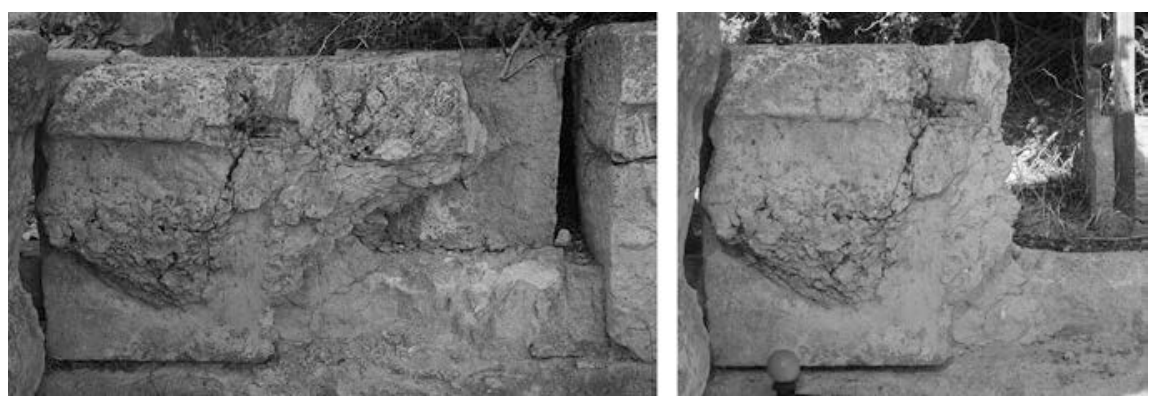

Figure 2. YB06 in 2012 (left) and 2016 (right)

(photos by Ömür Harmanşah and Müge Durusu-Tanrı̈ver, (C) Yalburt Yaylası Archaeological Landscape Research Project)

ment revealed the fast decay of the inscription and the disintegration of the blocks, very visible, for instance, on YB6 (Fig. 2). We decided to start a program of thorough documentation for the digital preservation of the hieroglyphic inscription, at which point Reflectance Transformation Imaging emerged as the best solution because of its low-budgetary requirements and ease of use.

Reflectance Transformation Imaging, or RTI, is a technique for recording the surface characteristics of an object. Multiple photographs are taken under different angles of light, and then stitched together using an open-access software. The result is a synthetic model (and in this case a Polynomial Texture Map - PTM), which can be viewed in a dynamic way by manipulating a virtual light source in real-time, meaning that the object can be viewed under different directions of light. This reveals details, erasures, and layers not visible to the naked eye in daylight ${ }^{10}$. Small objects can be photographed inside light domes with cameras attached to their apexes, enabling the automatic manipulation of light to produce 40-50 images of each object, each taken under a different direction of light ${ }^{11}$. In this setting, the lights are at pre-calculated locations on the intersection points of a tri-

10 Cultural Heritage Imaging 2019a.

11 Malzbender et al. 2001, 520-521. 
angular frame system, turning on and off according to the sequence detailed in the controlling software, which is then used as an input during the production of the final model. While PTMs of tablets ${ }^{12}$, red-figure Attic vases ${ }^{13}$, manuscripts ${ }^{14}$, faunal remains ${ }^{15}$, and even shipwreck remains ${ }^{16}$ have been collected using such domes, the scales in which archaeology is practiced in the field extend far beyond the small and the portable. Highlight-RTI has emerged as the alternative method for modelling larger objects; wherein the light dome is recreated, usually only partially, using manually manipulated external light sources ${ }^{17}$.

Highlight-RTI was used to record 17 carved limestone blocks during the 2014 and 2016 seasons of the Yalburt Yaylası Archaeological Landscape Research Project. In our pilot RTI session in 2014, we managed to record eight blocks over the course of a week, while the remaining nine were completed in another week during the 2016 season $^{18}$. Since scholarly consensus on the reading of some of the Hieroglyphic Luwian signs in the inscription has not yet been achieved, recording the surfaces in their current state of conservation will enable better future scrutiny of the monument in consequence of advances in Luwian studies. This, in return, will mean that the Yalburt Yaylası Sacred Pool Complex will continue to be a major source for reconstructing and discussing the history and archaeology of the final stages of the Hittite Empire.

In this paper, I offer a methodology for the use of Highlight-RTI on large, immobile monuments in the rural landscape by using the Yalburt Yaylası Sacred Pool Monument as a case study. While Highlight-RTI has been used in such settings before ${ }^{19}$, the Yalburt Monument offers a challenging example where multiple orientations, dimensions, and constraints forced us to create a tailored solution that emphasized consistency in the angles of the light source at the expense of ideal distances based on the measurements of the surfaces. Despite these constraints, this study shows that RTI can become an effective and efficient actor in the documentation and the preservation of cultural heritage in exposed landscapes. In this capacity, it is most effective when conceived as a site-specific technique, and customized to the particular needs of a locale by responding to the realities and challenges of an object/monument within its landscape context.

\section{RTI: A Brief Introduction}

The RTI technique centers around the idea of taking multiple photographs of a surface in exactly the same conditions except for the position of the light source. In this setting, the camera and the object being photographed must remain absolutely immobile, while the angle of the light changes in each photograph.

In the absence of the preset light locations of a light dome, the Highlight-RTI relies on a reflec-

12 e.g. Stolper 2009.

13 e.g. Artal-Isbrand et al. 2001.

14 e.g. Zaman et al. 2018.

15 e.g. Newman 2015.

16 e.g. Selmo et al. 2017.

17 e.g. Dellepane et al. 2006; Frood - Howley 2014; Diaz-Guardamino et al. 2015; Akçay 2016.

18 RTI work was pursued on top of the other archaeological fieldwork activities, which consequently resulted in longer times than usual for the imaging. In cases where the main work of the team could be primarily directed to RTI, these timeframes would of course be shorter.

19 e.g. Mudge et al. 2006; Frood - Howley 2014. 
tive sphere roughly the size of a billiard ball to record the angle of the light in different photographs. This sphere must be either black or red, and can be easily produced by drilling a hole in a plain billiard or juggling ball to mount it on a tripod. In ideal conditions, an RTI kit should include a camera with full manual control and the best possible lens for the object(s) to be photographed, reflective sphere(s), tripods for stabilizing both the camera and the reflective sphere(s), an external light source (a flash light or an external flash working in tandem with the camera for best results), and strings to easily measure a fixed distance between the camera and the object during set up, and the object and the light source in each photograph. In the original method, the light dome limited the distance between the surface being photographed and the apex of the light dome, where the camera is located, to three times the diameter of the object being photographed ${ }^{20}$. The Highlight-RTI method offers an inherent flexibility on this front, which was a crucial point for our work on the Yalburt Monument.

The resulting images, usually ca. 40-50, are uploaded into the open access software RTI Builder, developed by Cultural Heritage Imaging ${ }^{21}$. The user must mark the placement and color of the reflective sphere in the images for the software to successfully process the photographs into a model. Once the software can detect the borders of the sphere, it can then scan its surface for the reflection left by the artificial light source during photography. Extrapolating from that, the software can calculate the angle of light in each image. After the sphere detection is complete, the reflective spheres can be cropped from the image for a polished final product, and the software is left to process the images to produce the model. Another open access software, RTI Viewer, is then utilized to view and manipulate the composite image $e^{22}$. Here, the user can manually manipulate a virtual light source on the model in a dynamic way to study the details on the object not visible to the naked eye under regular daylight.

Like any other technique, RTI has its limitations. Firstly, it works on one surface at a time, and is not a 3D imaging tool that can model objects and spaces in the round. Second, the quality of the RTI product is directly dependent on the quality of the photographs, and the better the camera equipment and the photography are, the better the RTI results will be. This includes such parameters as the digital resolution of the camera used, the optical qualities of the accompanying lens, the stability of the camera during the capture and the overall quality of the images produced - all of which are dependent on the ability of the user to manually use the camera equipment in the best possible way for the specific object to be captured, as well as the quality of the equipment used. Third, RTI does not provide or record any quantitative data, such as measurements, and should not be utilized in place of vector-data-driven field recording techniques able to document measurements, angles, and distances. Finally, RTI can be a time-consuming process, especially when used on large monuments such as the example discussed in this paper. Despite these limitations, RTI offers a non-invasive method of recording for cultural heritage, which is particularly well-suited for the recording of surface detail, and which can be executed with relatively inexpensive equipment and open-source software. While RTI is a two-dimensional recording technique, the results provide a relief of the surface of the object, which can compete with three-dimensional recording tools. Furthermore, both the technique and the software have an easy learning curve, especially in cases where the user is already

\footnotetext{
20 Zányi 2007.

21 Cultural Heritage Imaging 2019b.

22 Cultural Heritage Imaging 2019c.
} 


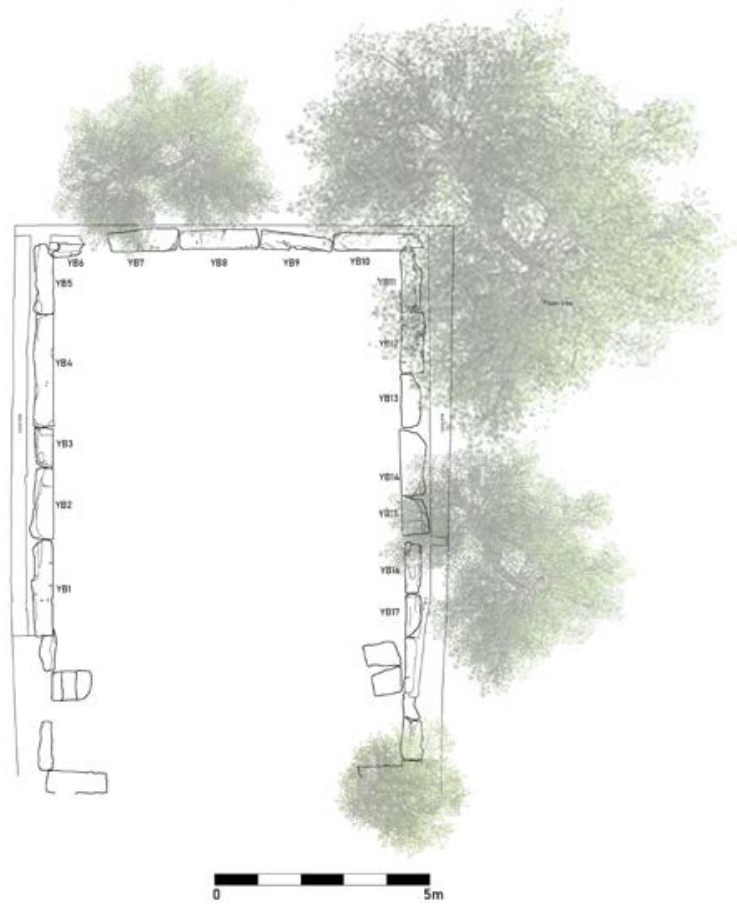

Fig. 3. Plan of the Yalburt Monument (after the drawing by Ömür Harmanşah and Nilgün Öz, (CYalburt Yaylası Archaeological Landscape Research Project)

familiar and comfortable with full manual control on a camera, enabling users to master the technique with relative ease and to find customized solutions. I now turn to one such example, where the Highlight-RTI approach was adapted to the needs of our survey project in Konya, in central Anatolia.

\section{Adapting Highlight-RTI for the Yalburt Monument}

From the outset, the Yalburt monument presented significant challenges to the adaptation of the RTI technique. Originally built as a rectangular pool, the monument now has three sides reconstructed from the discovered blocks (Fig. 3). This made it necessary to develop strategies for recording surfaces facing three different orientations. Varying orientations forced us to be flexible with the timing of the recording sessions, with each side requiring a particular time of day. While we could work in the early mornings for the northern and southern walls, we achieved the best results for the western façade during the late afternoons and early evenings. The blocks are also of diverse length, ranging from $69 \mathrm{~cm}$ to $272 \mathrm{~cm}$, meaning that there was not one single set-up strategy that could be developed to fit all the blocks, if we wanted to follow the more conventional RTI wisdom on ideal distances between the surface and the camera as dictated by the dimensions of the blocks ${ }^{23}$. Working with a semi-enclosed monument also meant that the distance from which photographs could be taken was constrained by the monument itself; it was impossible to achieve a distance of three or four times the length of the largest dimension of some blocks during the sessions. In the case of some medium-sized blocks, even if we could move the set-up that far, the external light source failed to illuminate the surface sufficiently. After much trial and error on different sized blocks, where the medium- and large-sized blocks were not producing crisp results due to the camera and light source being too far away, we decided to classify the blocks according to their sizes ( $\mathrm{S}, \mathrm{M}$, and L) (Table 1) and experiment with different distances. A two-meter radius for the light source (described in detail below) on YB2 produced the best results. After observing that YB2 is a medium-sized block, which are the most numerous in the monument, we made the critical decision to use a fixed set of distances for the camera and the light source, as well as fixed angles for the light source for all blocks that would be drawn from the success we had with YB2.

In the resulting set-up, we used a Canon EOS 40D Digital SLR Camera with 28-135 mm Canon Ultrasonic Lens f/3.5-5.6 IS USM with Image Stabilizer- Macro 0.5-1.6 ft. located firmly on a tripod $180 \mathrm{~cm}$ away from the central point of each block. The external light source, in our case a Canon

23 Mytum - Peterson $(2018,490)$ cites this distance to be four times the diameter or diagonal of the object. 


\begin{tabular}{|l|l|l|l|}
\hline & Small Blocks (S) & Medium Blocks (M) & Large Blocks (L) \\
\hline Dimensions & $0-100 \mathrm{~cm}$ & $101-180 \mathrm{~cm}$ & $181-272 \mathrm{~cm}$ \\
\hline Blocks & YB3, YB6 ${ }^{\star}, \mathrm{YB} 15, \mathrm{YB} 17$ & $\begin{array}{l}\text { YB2, YB5 } \\
\text { YB12, YB7, YB13, YB14, YB16 }\end{array}$ & YB1, YB4, YB8, YB10 \\
\hline $\begin{array}{l}\text { Camera-block distance } \\
\text { External light source - } \\
\text { block distance }\end{array}$ & $180 \mathrm{~cm}$ & $180 \mathrm{~cm}$ & $180 \mathrm{~cm}$ \\
\hline $\begin{array}{l}\text { Divisions along the hori- } \\
\text { zontal axis }\end{array}$ & 18 & $200 \mathrm{~cm}$ & $200 \mathrm{~cm}$ \\
\hline $\begin{array}{l}\text { Degree change along the } \\
\text { horizontal axis for each } \\
\text { new set }\end{array}$ & $10^{\circ}$ & 24 & 36 \\
\hline $\begin{array}{l}\text { Distance along the half- } \\
\text { circle }\end{array}$ & $34.9 \mathrm{~cm}$ & $7.5^{\circ}$ & $5^{\circ}$ \\
\hline $\begin{array}{l}\text { Divisions along the verti- } \\
\text { cal axis }\end{array}$ & 5 & $26.1 \mathrm{~cm}$ & $17.4 \mathrm{~cm}$ \\
\hline \begin{tabular}{l} 
Target photo number \\
\hline ×
\end{tabular} & 114 & 5 & 5 \\
\hline
\end{tabular}

* Since these blocks are obstructed on one end, $180^{\circ}$ horizontal coverage was not possible, and we handled them as if they were L-sized blocks.

Table 1. Basic classification system and the recording strategies for the blocks

Speedlite 430 EXII -24-105mm auto zoom head external flash, traveled on a virtual half-circle with a two-meter radius as measured by a string. A red billiard ball stabilized on another tripod was used for recording the reflection in each photograph. Having the camera in front of the light source ensured that the light source, and the person holding it, would not be in the photographs. However, it also meant that when the light source was directly behind the camera, the camera would hinder the light. These photographs needed to be discarded during the processing of the images into the final PTM. Using set dimensions for the location of the camera for 17 blocks of varying sizes pushed us to find a calibration mechanism to achieve a comparable consistency across the monument. The result was utilizing different divisions along the virtual halfcircle on which the light source was traveling. We utilized 18, 24, and 36 divisions on $\mathrm{S}, \mathrm{M}$, and $\mathrm{L}$ blocks, respectively; corresponding with $10^{\circ}, 7.5^{\circ}$ and $5^{\circ}$ angles (Fig. 4 ).

Another set of decisions needed to be made about how the light would behave vertically. While
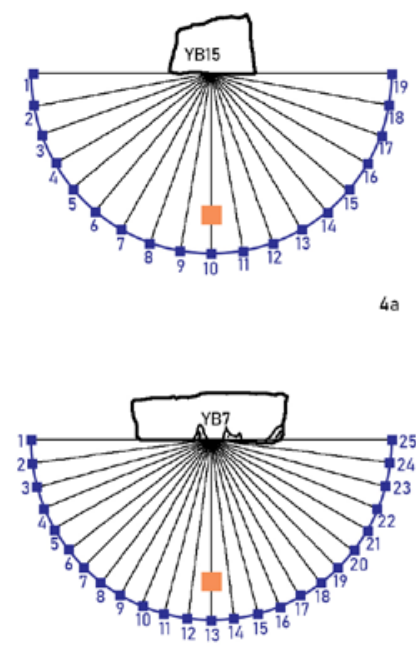

$4 b$
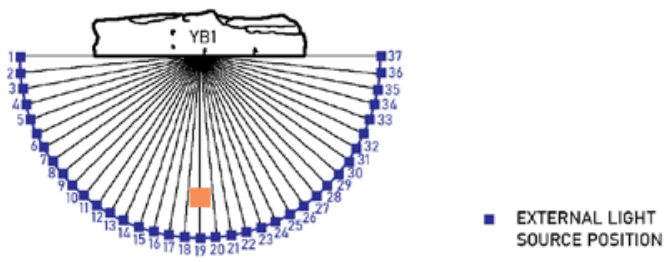

$4 \mathrm{C}$ CAMERA

Fig. 4. Top view demonstrating the angles used for horizontal sets of $S(a), M(b)$ and $L(c)$ blocks 
the length of the blocks varied considerably, their heights were uniform (c. 80 centimeters), making it easier to plan a consistent strategy for how the external light source would move along the vertical axis. As the inscribed blocks of the Yalburt Monument sit on base stones that are $50 \mathrm{~cm}$ high, the lowest possible angle to hit the stones was fixed at $346^{\circ}\left(-14^{\circ}\right)$. Trying to strike a balance between the lowest position of light and the highest, while also being pressed for time in the intense fieldwork schedule of the season, we experimented with a two-meter vertical set-up and acquired good results. Five vertical divisions corresponding to six virtual points on the blocks with $19^{\circ}, 13^{\circ}, 6^{\circ}, 359^{\circ}, 352^{\circ}$, and $346^{\circ}$, from highest to lowest points respectively enabled us to cover in a total $\operatorname{arc}$ of $33^{\circ}$ (Fig. 5).

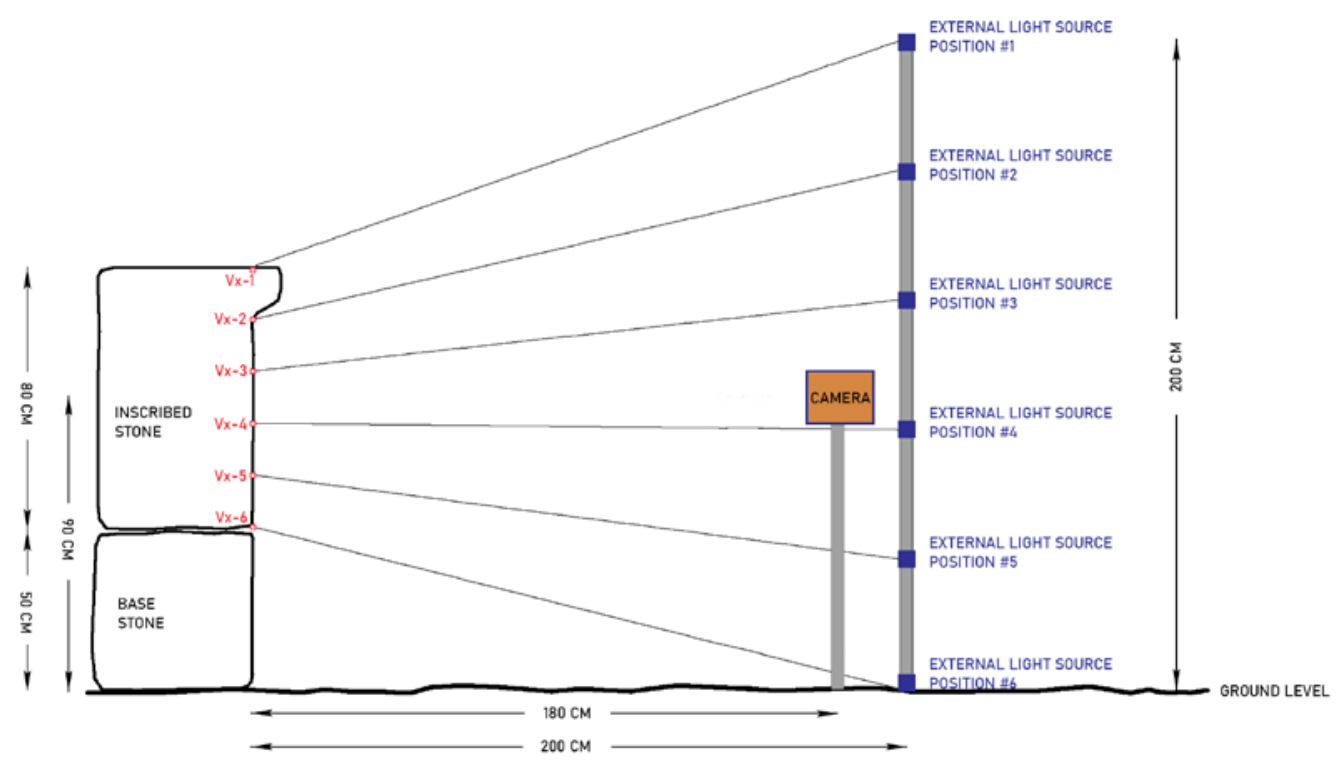

Fig. 5. Elevation demonstrating the setup used for each vertical set

Once this system had been designed, the next step was to translate it into actual images produced in the field. Working in a team of three, one person was responsible for the camera set-up and taking the photos, another for holding and moving the external light source along the arc determined by a string, and a third holding the other end of the string next to the block, providing checks for the distance and the angle - and moving before each image was taken (also known as 'The Egyptian Method') ${ }^{24}$. The first vertical set always started with the external flash being held two meters to the left of the midpoint of the block in Position 1 (Fig. 4), immediately adjacent to the neighboring block(s) on the left, and two meters above the ground ( $\mathrm{Vx}-1$ in Fig. 5). Afterwards, without anyone moving, the person in front of the block lowered one end of the string $16 \mathrm{~cm}$ to Vx-2 (Fig. 5), while the person holding the external flash lowered the light source $40 \mathrm{~cm}$ to provide a $13^{\circ}$ angle. This was repeated four more times until the first vertical set was completed. Afterwards, the person holding the external flash moved $35 \mathrm{~cm}, 26 \mathrm{~cm}$, or $17.5 \mathrm{~cm}$ depending on the size of the block (Table 1), and raised the flash to two meters above the ground, while the team member by the block turned the string back to the $\mathrm{Vx}-1$ position. This procedure was repeated for 19,25 , or 37 times in total for S, M, and L- sized blocks, respectively, for a total of 114, 150, or 222 photos depending on the size of the block (see Fig. 6 for an example set that can be followed through the reflections on the red billiard ball). While these numbers are excessive in comparison with other, mainly indoor RTI captures, our aim was to document as much as possible so that discarding any photographs

24 Zányi 2007,224; Earl et al. 2010, 2043. 

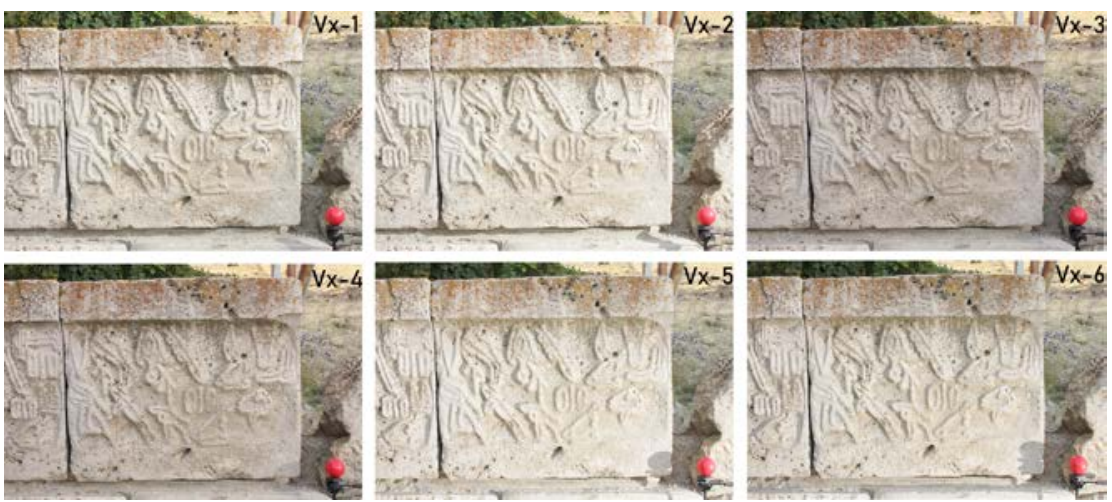

Fig. 6. The reflection of the light on the surface of YB15 throughout a vertical set
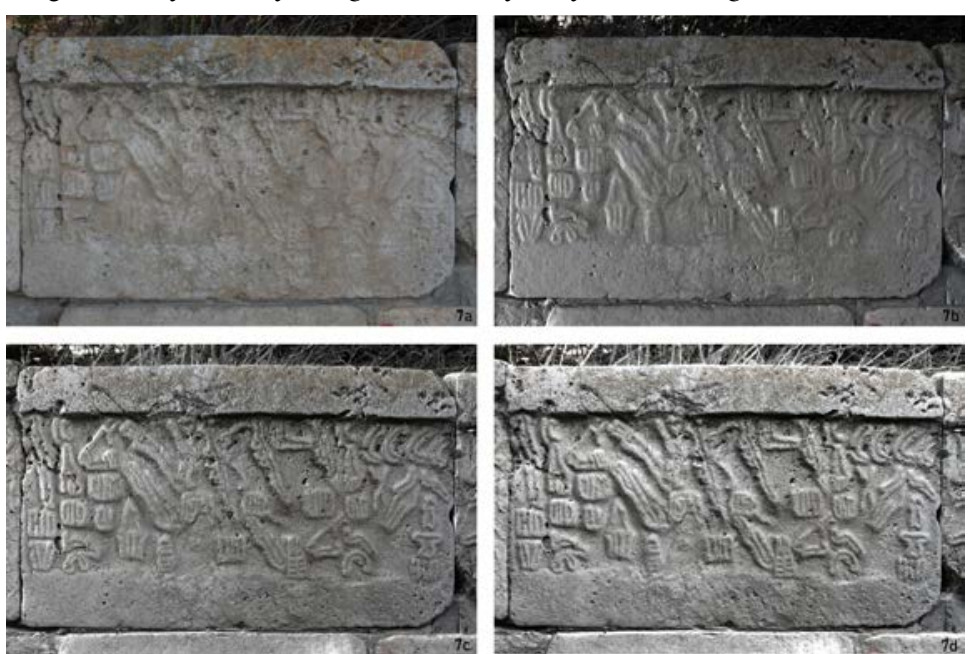

Fig. 7. Regular photograph of YB13 (a, top left) and composite RTI images with different light orientations (b-d)
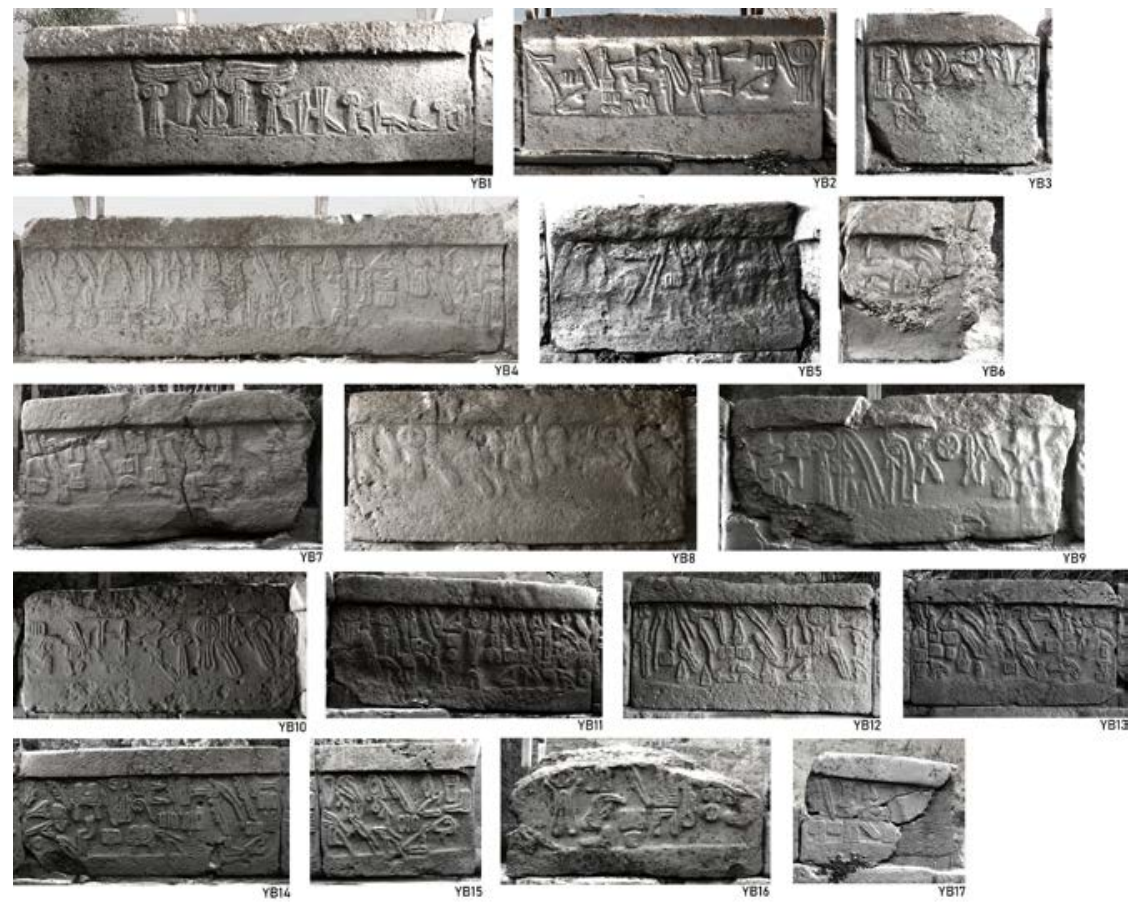

Fig. 8. Example RTI snapshots of all the blocks 
with shadows, blurry captures, or fieldwork misfortunes would still leave us with a substantial number of images for each block. In the end, a $180^{\circ}$ horizontal coverage was paired with a $33^{\circ}$ vertical one. While this cannot compete with the total $180^{\circ}$ coverage of a light dome in both the vertical and horizontal axes, subdivided into 40-50 positions at the intersections of a triangular frame system embedded into the dome, the operation described above within the limited amount of time we had enabled us to obtain sufficient detail.

This strategy had to be altered yet again for four blocks standing at the intersection points of the rectangular pool. For YB5, YB6, YB10, and YB11, we could only cover a $90^{\circ}$ arc. To compensate, these four blocks were handled as if they were all L-sized and were divided into $5^{\circ}$ sets in horizontal coverage to maximize the number of photos taken regardless of their size. While the resulting composite images were of decidedly lesser quality than their counterparts, they represent the best possible practice within the given site conditions.

\section{Conclusions}

The methodology described above presents an ideal scenario envisioned for the RTI work undertaken by the Yalburt Yaylası Archaeological Landscape Research Project team in 2014 and 2016. In reality, fieldwork conditions, including the non-negotiable dates of the season, dying batteries, windy days shaking the camera, and even sheep overrunning the blocks during particular times of the day, pushed us into being even more flexible. In each set of photographs, there were blurry or dark images that needed to be discarded, leaving us with photograph counts lower than our target. However, even under these circumstances, RTI rewarded us with models that rendered the inscription much more legible than with the naked eye (Fig. 7-8), revealing that the software can compensate for fieldwork misfortunes. The flexibility embedded in the technique and the software makes RTI an extremely productive approach for recording landscape monuments, as long as a process of customization is achieved to respond to the local realities of each site. In our case, the system described in detail above was directly dependent on the specific circumstances of Yalburt Yaylası Sacred Pool Monument - ranging from the distance of the blocks from the ground to the arrangement of the inscription around three sides. This provides a replicable model for other landscape monuments containing surfaces of different orientations and dimensions to be recorded in the rural landscape. After carefully analyzing the physical constraints imposed on us by the monument, we designed a set of light angles to illuminate the blocks during imaging. These angles were controlled by using strings between set spots on the $80 \mathrm{~cm}$ block surfaces and a two-meter vertical set-up for the external light source located along a half-circle with a two-meter diameter. By varying the number of horizontal stops, we were able to take more images for larger blocks, and fewer for smaller ones, enabling us to produce final models presenting blocks of different sizes in comparable detail.

Considering the current stress on the monument, including the metal rods embedded in the blocks and weather conditions, the digital recording of the 17 blocks on site at Yalburt Yaylası will enable current and future scholars to revisit the Yalburt inscription in light of advances in the scholarship on the Luwian language, and will continue to be an important source for constructing the later part of Hittite history. The RTI models of all the blocks and the accompanying photographs are now in the process of being migrated to a digital platform for wider dissemination among scholars and enthusiasts of Bronze Age Anatolia ${ }^{25}$.

25 The stills in this paper fail to do justice to the dynamic capability of the final RTI models. Multiple platforms are being explored at the time of writing for a dynamic digital exhibition of the RTI models that will enable the users to engage with 


\section{BIBLIOGRAPHY}

Akçay 2016

Artal-Isbrand et al. 2010

A. Akçay, "Epigrafi Araştırmalarında Yeni Bir Belgeleme ve Analiz Metodu olarak RTI”. MJH VI/2 (2016) 1-16.

P. Artal-Isbrand, P. Klausmeyer - W. Murray, "An Evaluation on Decorative Techniques on a Red-Figure Attic Vase from the Worcester Art Museum using Reflectance Transformation Imaging (RTI) and Confocal Microscopy with a Special Focus on the 'Relief Line"'. MRS Online Proceedings (2010) 1319.

Cultural Heritage Imaging 2019a

Cultural Heritage Imaging 2019b

Cultural Heritage Imaging, Reflectance Transformation Imaging (RTI). 2019 http://culturalheritageimaging.org/Technologies/RTI/

Cultural Heritage Imaging, Process: RTIBuilder Download. 2019. http://culturalheritageimaging.org/What_We_Offer/Downloads/Process/i ndex.html.

Cultural Heritage Imaging 2019c

Cultural Heritage Imaging, View: RTIViewer Download. 2019. http://culturalheritageimaging.org/What_We_Offer/Downloads/View/ind ex.html.

Dellepiane et al. 2006

M. Dellepiane, M. Corsini, M. Callieri - R. Scopigno, "High Quality PTM Acquisition: Reflection Transformation Imaging for Large Objects”. Eds. M. Ioannides, D. Arnold, F. Niccolucci - K. Mania VAST06: Proceedings of the $7^{\text {th }}$ International Symposium on Virtual Reality, Archaeology and Cultural Heritage, Eurographics Digital Library (2006) 179-186.

Díaz-Guardamino et al. 2015 M. Díaz-Guardamino, L. G. Sanjuán - D. Wheatley, "RTI and the Study of Engraved Rock Art: A Re-Examination of the Iberian South-western Stelae of Setefilla and Almadén de la Plata 2 (Seville, Spain)". Digital Applications in Archaeology and Cultural Heritage 2 (2015) 41-54.

Earletal. 2010

G. Earl, K. Martinez - T. Malzbender, "Archaeological Applications of Polynomial Texture Mapping: Analysis, Conservation and Representation”. Journal of Archeological Science 37 (2010) 2040-2050.

Frood - Howley 2014 E. Frood - K. E. Howley, "Applications of Reflectance Transformation Imaging (RTI) in the Study of Temple Graffiti”. Eds. Elena Pischikova, Jula Budka - Kenneth Griffi Thebes in the First Millennium BC, Cambridge Scholars Publishing, Newcastle upon Tyne (2014) 625-638.

Harmanşah - Öz 2018 Ö. Harmanşah - B. N Öz, Yalburt Yaylast Hitit Kutsal Pınar Havuzu Mimari Koruma ve Arkeolojik Alan Yönetimi Önerileri Raporu (report submitted to the Ministry of Culture and Tourism of Turkey). 2018.

Harmanşah et al. 2014 Ö. Harmanşah, P. Johnson - M. Durusu-Tanrı̈ver, "Yalburt Pınarı̉nda Bir Hitit Kralı: Tunç Çağı, Soğuk Sular ve Anadolu Peyzajı”. Aktüel Arkeoloji 37 (2014) 10-15.

Harmanşah et al. 2017 Ö. Harmanşah, P. Johnson, M. Durusu-Tanrı̈̈ver - B. Marsh, "Lake-Places,

the inscription. The reader is invited to follow the Yalburt Yaylası Archaeological Landscape Research Project Website (https://www.yalburtproject.org/) and the associated social media accounts for updates on this process. 
Hawkins 1995

Malzbender et al. 2001

Mudge et al. 2006

Mytum - Peterson 2018

Newman 2015

Selmo et al. 2017

Stolper 2009

Temizer 1984

Zaman et al. 2018

Zányiet al. 2007
Local Hydrology, and the Hittite Imperial Projects in the Ilgin Plain: Yalburt Yaylası Archaeological Landscape Research Project 2015-2016 Seasons". Eds. S. R. Steadman - G. McMahon, The Archaeology of Anatolia Volume II: Recent Discoveries (2015-2016). Newcastle upon Tyne (2017) 297-315.

J. D. Hawkins, "Appendix 1: Yalburt". The Hieroglyphic Inscription of the Sacred Pool Complex at Hattusa (SUDBURG), with an Archaeological Introduction by Peter Neve. Wiesbaden (1995) 66-85.

T. Malzbender, D. Gelb - H. Wolters, "Polynomial Texture Maps". ACM SIGGRAPH Computer Graphics 2001 (2001) 519-528.

M. Mudge, T. Malzbender, C. Schroer - M. Lum, "New Reflection Transformation Imaging Methods for Rock Art and Multiple-Viewpoint Display". Eds. M. Ioannides, D. Arnold, F. Niccolucci - K. Mania VAST06: Proceedings of the $7^{\text {th }}$ International Symposium on Virtual Reality, Archaeology and Cultural Heritage, Eurographics Digital Library (2006) 195-200.

H. Mytum - J. R. Peterson, "The Application of Reflectance Transformation Imaging (RTI) in Historical Archaeology”. Historical Archaeology 52 (2018) 489-503.

S. E. Newman, "Applications of Reflectance Transformation Imaging (RTI) to the Study of Bone Surface Modifications". Journal of Archaeological Science 53 (2015) 536-549.

D. Selmo, F. Sturt, J. Miles, P. Basford, T. Malzbender, K. Martinez, C. Thompson, G. Earl - G. Bevan, "Underwater Reflectance Transformation Imaging: A Technology for in Situ Underwater Cultural Heritage ObjectLevel Recording". Journal of Electronic Imaging 26/1 (2017).

M. W. Stolper, "Persepolis Fortification Archive Project". The Oriental Institute 2008-2009 Annual Report (2009) 104-111.

R. Temizer, "Introduction". Ed. T. Özgüç, Inandıktepe: An Important Cult Center in the Old Hittite Period. Ankara (1984) xxiii-xxxii.

T. Zaman, D. Howell - L. Snijders, "Imaging Mexican Codices, Challenges and Opportunities". Eds. M. E. R. G. N. Jansen, V. Lladó-Buisán and L. Snijders Mesoamerican Manuscripts: New Scientific Approaches and Interpretations. Leiden (2018) 380-395.

Zányi, Eva, Carla Schroer, Mark Mudge - Alan Chalmers, "Lighting and Byzantine Glass Tesserae". Proceedings of the EVA London Conference, 11-13 July 2007.

https://pdfs.semanticscholar.org/d6db/de646d178e89bd4f17ce8a1719ba12 5d4e08.pdf. 